\section{Problemas en la lexicalización en español de términos culturales japoneses: análisis y propuesta tipológica de errores con el diccionario Sakura como caso de estudio}

Cuadernos CANELA, 29, pp. 78-99

Recibido: 18-X-2017

Aceptado: 13-II-2017

Publicado, versión impresa: 26-V-2018

ISSN 1344-9109

Publicado, versión electrónica: 26-V-2018

ISNN 2189-9568

(C) El autor 2018 canela.org.es

\author{
Alberto Millán Martín \\ Universidad Keio, Tokio, Japón
}

\title{
Resumen
}

Aunque el número de japonesismos utilizados en la lengua española es cada vez mayor, no existen estudios cualitativos que hayan analizado si la transferencia de conceptos desde la cultura japonesa a la nuestra se ha realizado desde una práctica rigurosa que nos permita comprender bien la idiosincrasia de esa civilización. Este trabajo explora los principales problemas detectados en la lexicalización de términos culturales japoneses, especialmente los errores de carácter semántico, tomando como caso de estudio el diccionario de cultura japonesa Sakura de la editorial Satori (2016), obra académica especializada única en español, elaborada con la participación de numerosos especialistas. Basándonos en nuestra triple perspectiva de las teorías del cambio lingüístico, los estudios de traducción y la comunicación intercultural, proponemos una tipología de errores analizables mediante categorías no excluyentes entre sí, con el fin de facilitar una muestra orientativa encaminada a la detección y prevención de errores similares en futuros trabajos.

\section{Palabras clave}

Préstamo, japonesismo, marcador cultural, traducción, análisis de errores

\section{Introducción}

A lo largo de los años, la lengua española ha venido incorporando multitud de términos procedentes de Japón que hacen referencia a conceptos específicos de su civilización («marcadores culturales»). Aunque los más conocidos como «samurái», «quimono»o «sumo» están recogidos por el Diccionario de la lengua española de la RAE (2014), existe una mayoría de términos especializados que se mantienen como extranjerismos utilizados en sus respectivos ámbitos. Pensamos que la introducción de esta terminología se produce de dos maneras: espontánea [indirecta], cuando en ocasiones puntuales se recurre a voces japonesas por necesidad (ausencia de equivalencias en castellano) o pretensión exotizante; o deliberada [directa], cuando de forma metalingüística se pretende introducir términos específicos, con sus correspondientes definiciones o explicaciones, para que puedan ser utilizados por profesionales (investigadores, traductores, periodistas...) o por el público general. En ambos casos, no son pocas las veces en que se producen errores lexicográficos en la transliteración de palabras japonesas a nuestra escritura alfabética, en la interpretación de sus características morfológico-sintácticas o en la comprensión y transmisión de su correcto significado, siendo este último caso el que más nos preocupa. 
Desde un punto de vista ontológico, consideramos que es interesante conocer la naturaleza de este tipo de errores (problemas de lexicalización de japonesismos con marcada carga cultural) para saber si se generan de manera aleatoria o existe cierta reproducción de pautas comparables con algún marco teórico existente. Desde una perspectiva más práctica o funcional, nos parece necesario analizar dichos problemas en los casos de introducción deliberada [directa] a través de obras lexicográficas especializadas que, al gozar de la credibilidad que les otorga el marchamo académico e institucional, pueden ejercer una gran influencia sobre aquellos hispanohablantes que las utilicen como referencia o fuente de autoridad.

En este contexto y con estas motivaciones en mente, los objetivos específicos del presente estudio consistirán en identificar los problemas existentes a la hora de comprender términos culturales japoneses y definirlos en español, analizar los cambios lingüísticos y errores que se producen cuando los conceptos se trasvasan a nuestra cultura, tratar de reconocer tendencias sistemáticas generales en el proceso de lexicalización y, por último, proponer una tipología simplificada basada en categorías flexibles que sirva para entender la naturaleza de diferentes errores y poder evitarlos.

Como objetivos generales de nuestra investigación, esperamos poder contribuir a otros estudios similares a mayor escala sobre la transferencia de conceptos de una cultura a otra, ya sea desde el punto de vista de la lingüística, de la traductología, de la comunicación intercultural o de la didáctica de lenguas extranjeras.

\section{Caso de estudio}

Como primera aproximación a este tema de estudio, hemos decidido centrarnos en los japonesismos introducidos de forma deliberada [directa] en obras lexicográficas especializadas, por los motivos y objetivos arriba expuestos. La obra que hemos tomado como caso de estudio no solo es el único diccionario técnico de cultura japonesa publicado en español de manera reciente y elaborado por expertos, sino que además tiene un marcado carácter académico y podría ejercer una gran influencia en la futura lexicalización y uso de japonesismos en nuestra lengua. Sakura. Diccionario de cultura japonesa: japonés-españolinglés de Flath, Orenga, Rubio \& Ueda fue publicado en 2016 por la editorial gijonesa Satori, como parte de la incontestable difusión de la literatura y la cultura de Japón que ha venido realizando en los últimos años. En sus páginas se asegura que recoge más de tres mil términos (de un corpus inicial de seis mil) seleccionados según su representatividad, frecuencia de uso y dispersión en diferentes áreas temáticas. Su aparición está motivada por tres factores: «la madurez de los estudios japoneses en lengua española», «la popularidad sostenida, y no ya pasajera moda, de la cultura japonesa en Occidente» y «el deseo de poner en manos del traductor del japonés al español o al inglés una obra de fácil manejo y consulta fiable» (p.13). Esto último no es óbice para que también esté dirigido, según se afirma, a cualquier persona interesada total o parcialmente en la cultura japonesa. A lo largo de los textos introductorios y de los paratextos (prólogos, contracubierta...) se insiste en el rigor científico, la seriedad académica y la precisión con que han sido elaboradas las didácticas definiciones, siempre desde un conocimiento profundo de la realidad japonesa y la voluntad de tender puentes de entendimiento entre culturas.

Además, este ambicioso diccionario, de carácter pionero y voluntad indisimulada de convertirse en obra de referencia en el sector, está publicado con una ayuda a la edición del Ministerio de Educación, Cultura y Deporte; prologado por el Embajador de Japón en España 
y el de España en Japón; y elaborado por cuatro expertos en lingüística, filología y traducción ${ }^{1}$ con el asesoramiento directo de treinta especialistas nombrados en la introducción, así como con la colaboración de 180-200 informantes, especialmente profesores y traductores. Por todo ello nos parece una obra lo suficientemente representativa de los principales problemas que podemos encontrar: algunos de los errores analizados se producen en el propio diccionario, pero otros habrán sido heredados a través de las consultas en otras obras o a otros expertos.

Al respecto de las fuentes utilizadas por los autores, la presencia de publicaciones monolingües en japonés que se citan en la bibliografía (pp. 33-34) bajo el epígrafe «Diccionarios, manuales, enciclopedias y revistas» es testimonial: los conocidos diccionarios Kōjien y Daijirin. El resto son tres obras en español, cuatro en inglés y cinco diccionarios bilingües del japonés al español o al inglés. En una segunda categoría titulada «Glosarios de obras especializadas» figuran trece monografías en inglés y siete en español (cuatro de la misma editorial). Esta carencia de fuentes originales japonesas - todavía común en el mundo de la japonología en español— quizás sea una de las principales causas de los numerosísimos problemas encontrados.

En cuanto a nuestra metodología, primero efectuamos una lectura rápida completa del diccionario, recopilando problemas que nos parecieron desde imprecisiones cuestionables hasta errores innegables. Sin entrar en comprobaciones exhaustivas sobre ámbitos léxicos que no dominamos bien (botánica, cerámica, peinado...), obtuvimos un primer listado de más de un centenar de entradas con problemas (una de cada treinta), de las cuales en este trabajo mostramos alrededor de un tercio.

Con ese primer corpus nos pusimos a trabajar en el marco teórico para tratar de hallar pistas que nos permitieran hacer una clasificación de errores propia de las definiciones léxicas y llegamos a tres conclusiones: 1) que el enfoque de los estudios precedentes sería incompleto e insuficiente y necesitaríamos recurrir a varias disciplinas, 2) que las diferentes categorías no podrían ser compartimentos estancos y un solo error debería poder ser clasificado en varias tipologías, y 3) que no era factible ni necesario distinguir cada categoría de problema / error según si era un tipo de causa o un tipo de resultado. Esto nos condujo a la idea final de elaborar nuestra propuesta tipológica, no con intención puramente clasificatoria, sino a modo de lista de verificación que pueda servir para evitar errores en la producción de definiciones en particular y textos en general. También, por este motivo, nos pareció adecuado que nuestro análisis de errores tenga un enfoque cualitativo, no cuantitativo o estadístico.

\section{Marco teórico}

\subsection{Estudios previos: el enfoque lexicográfico}

Entendemos que un japonesismo es un préstamo léxico tomado de la lengua japonesa. Y un préstamo es, según la concisa definición de García Yebra (1994, p.279), una «palabra o expresión que una lengua toma de otra sin traducirla». Autores como Seco (1977, p.197) diferencian los extranjerismos crudos de los adaptados según su grado de asimilación gráfica y fonética, mientras que trabajos más recientes como el de Gómez Capuz (1998, p.214) han resaltado que existe un continuum entre los diferentes estadios difícil de delimitar. En el caso de los japonesismos, consideramos que la mayoría son extranjerismos porque, incluso aunque se hayan adaptado y naturalizado, los hablantes aún los perciben como voces tomadas de otro idioma. ${ }^{2}$ 
La mayoría de estudios sobre la incorporación de extranjerismos al léxico académico del español se centran en ese aspecto ortográfico (Buenafuentes \& Sánchez, 2012; Giménez Folqués, 2012). Nosotros pensamos que si la RAE (2014) ha naturalizado términos como «samurái», «bonsái», «manga» o «daimio» (en redonda) pero no otros como «geisha», «sushi» o «bushido» (en cursiva) no es debido a una mayor penetración o asimilación cultural de los primeros, sino a la dificultad que presentan los segundos: sería necesario sustituir el dígrafo $s h$ por $s$ / ch (cf. «sogún» / «champú») y representar correctamente la pronunciación sonora de la $g$; esto daría lugar a formas novedosas y arriesgadas como «susi / suchi» o «gueisa», que ni la RAE ni los hablantes parecemos dispuestos a incorporar de momento.

Además, entre las causas por las que ciertos extranjerismos no terminan de adaptarse a las convenciones ortográficas españolas, Hourani (2012, p.126) señala algunas como la familiarización de los hablantes con las grafías extranjeras («whisky») o el hecho de que designen «realidades que solo existen en el ámbito de la lengua de origen, sharia o sheriff». Para estas últimas, Gómez Capuz (2009) prefiere reservar el término xenismo. En el caso del japonés, nosotros apreciamos una tendencia extranjerizante al mantenerse la $k$ («kamikaze», «karaoke», «sake») incluso en formas que ya fueron naturalizadas («katana/catana», «kimono/quimono»).

Quizás el estudio más relevante sobre japonesismos en el idioma español sea la reciente tesis doctoral de Fernández Mata (2016), que solo menciona, sin analizar, cuatro trabajos previos muy breves. Hemos comprobado que dos de ellos (Kim, 1992; Frago Gracia, 1997) tienen una orientación histórico-filológica, de carácter más académico, centrada en unos pocos términos; mientras que los otros dos (Reyes Díaz, 2004; Cid Lucas, 2009) presentan un enfoque más generalista y divulgativo. El trabajo de Fernández Mata, en cambio, recopila y analiza hasta 111 japonesismos, haciendo un exhaustivo análisis comparativo de su tratamiento en varios diccionarios de la lengua española y de su primera aparición registrada en los corpus en línea de la RAE, para centrarse luego en valorar su grado de incorporación al sistema morfosintáctico español. Sin embargo, no encontramos un análisis semántico profundo de los cambios producidos en el trasvase de una lengua a otra, ni tampoco una evaluación crítica hecha desde el conocimiento de la lengua y la cultura de Japón.

Con el fin de suplir las carencias de los estudios precedentes, centrados en el grado de integración al sistema fonológico y ortográfico del español — la forma-, proponemos hacer un análisis de los problemas más frecuentes en la lexicalización de japonesismos en comparación con sus significados o usos primigenios - el contenido-, desde la triple perspectiva que exponemos a continuación.

\subsection{Nuevas perspectivas de análisis: un enfoque multidisciplinar}

\subsubsection{Desde la Lingüística: los procesos de cambio lingüístico}

Una de las hipótesis iniciales de nuestro estudio fue comprobar si los procesos de cambio lingüístico que tienen lugar en la evolución natural de las lenguas [nivel diacrónico] se reproducen de manera similar en un contexto interlingüístico e intercultural, esto es, a la hora de reproducir términos e interpretar conceptos de otra civilización en nuestra propia lengua [nivel sincrónico]. Para ello nos centramos en el cambio semántico y tuvimos en consideración diferentes tipologías presentes en Stern (1931), Bloomfield (1933), Ullmann (1951, 1962), Blank (1999) o Grzega \& Schöner (2007). Enseguida nos dimos cuenta de que la mayoría de procesos ya identificados, como la metáfora, intervienen de manera natural a la 
hora de dar nuevos usos a términos japoneses introducidos con anterioridad: «un tsunami de críticas», «hacerse el harakiri político». Sin embargo, nuestra intención no es analizar estos cambios legítimos que ya han sido incorporados a nuestro léxico, sino detectar accidentes generados durante procesos cognitivos, psicológicos, socioculturales o metodológicos: es decir, errores en el análisis, comprensión y uso de términos culturales que generalmente no perduran en el lenguaje cuando individuos aislados los utilizan de manera espontánea, pero que pueden sentar precedentes duraderos cuando se introducen de forma deliberada en obras lexicográficas de carácter prescriptivo o divulgativo (como corresponde a nuestro caso de estudio).

Así, para poder elaborar una tipología simplificada de problemas principales destinada a identificar posibles errores con el fin de poder evitarlos, nos basaremos en una clasificación lógica con criterios inequívocamente identificables. Esta se centra en tres categorías orientadas a las consecuencias y presentes en la mayoría de autores, que nosotros hemos adoptado así: restricción, ampliación y transferencia de significados. Prescindiremos pues de los criterios psicológicos basados en tropos lingüísticos (metáforas, metonimias...) que atañen a las causas porque en los casos analizados estas las encontramos en otros factores como la falta de conocimientos sobre el sistema lingüístico-cultural japonés o los fallos de transmisión de sentidos (errores de traducción). Añadiremos empero la categoría de etimologías populares, presente en varios autores, porque es un fenómeno frecuente y bastante particular.

\subsubsection{Desde la Traductología: los errores de traducción}

Muchas de las definiciones de términos culturales japoneses que encontramos en textos académicos y diccionarios son o podrían ser traducciones o paráfrasis de las explicaciones recogidas en otras obras de referencia escritas en inglés o japonés. A esto se debe que aplicar un enfoque traductológico nos haya ayudado a entender muchos de los problemas encontrados. La rama de la traductología que nos ha sido más útil es la de los estudios descriptivos, basados en datos empíricos reales — concretamente el análisis de errores-, desde un enfoque sociocultural y con una posible utilidad en los estudios aplicados (didáctica de la traducción) (Hurtado, 1996).

En cuanto al análisis de errores, Palazuelos, Vivanco, Hörmann \& Garbarini (1992) señalan como objetivo teórico de estos estudios ofrecer una explicación a dos preguntas: por qué se producen los errores y qué características lingüísticas tienen. La primera cuestión, que es de naturaleza psicológica, se corresponde con las causas (traducción-proceso); la segunda atañe al resultado (traducción-producto). Trataremos de tener en cuenta ambos aspectos, aunque solo el segundo se puede analizar con total objetividad.

Cada problema encontrado pasaremos a considerarlo un «error» según el criterio de Palazuelos et al. (1992): una «transgresión» o «desviación» respecto de un «saber» y un «deber» determinados. En nuestro caso, el saber entender el concepto designado por cada japonesismo y el deber de reproducirlo adecuadamente en nuestra lengua. Entenderemos por designación aquello que Coseriu (1977) considera una referencia a las «cosas», «hechos» o «estado de cosas» de carácter extralingüístico; esto es en nuestro caso las realidades culturales que se intenta transmitir a la cultura meta mediante definiciones lexicográficas, haciendo uso de los significados existentes y disponibles en la lengua de llegada. Sobre lo que se considera adecuado, tomaremos prestado el concepto general de Kussmaul (1995) y consideraremos «faltas de adecuación» los errores de aquellas explicaciones o ejemplos de uso que no se ajusten a la realidad de lo que pretenden transmitir (la designación y el sentido 
originales) o al nivel cognitivo del receptor, esto es, al objetivo didáctico y de referencia propio de una definición de diccionario. De esta forma, intentaremos compaginar el principio de adecuación de los estudios descriptivos con el de la perspectiva funcionalista.

Para ello tendremos en cuenta las teorías de Hatim \& Mason (1997), quienes consideran que los errores puntuales deben evaluarse en relación con un requisito global; Nord (1991, 1996, 2010), que habla de cumplir el encargo de traducción en relación con sus objetivos funcionales; y Hurtado (2001), que considera el error como una «equivalencia inadecuada» para la tarea traductora encomendada. Además, en relación con la «adecuación» de un texto a la situación comunicativa, Reiss \& Vermeer (1996, pp. 122-123) recuerdan la importancia de elegir signos lingüísticos que tengan en cuenta la «diferencia significativa de los conocimientos previos» del lector de la cultura final respecto del de la original. Algo que concuerda con la necesidad expresada por Nord (2010, p.126) de «anticiparse a cualquier malentendido o conflicto comunicativo que pueda surgir» y «encontrar una manera de evitarlos y resolverlos». Asumimos que en nuestro caso de estudio el objetivo funcional consiste en lexicalizar japonesismos en español definiendo, de manera inteligible y rigurosa, conceptos de la cultura japonesa, partiendo de la base de que muchos lectores no la conocen en profundidad. Asimismo, tomaremos como «unidad de traducción» (Nord, 1998) cada una de las entradas léxicas al completo (lema, definición, ejemplos...).

Sobre la tipología de errores, mientras que algunos autores como Pym (1992) destacan la dificultad de establecer categorías e incluso dudan de su necesidad, la mayoría de teóricos han intentado crear sus propios sistemas, que vemos comparados y analizados en detalle en Waddington (2001). Algunas deficiencias de las categorías tradicionales como analizar causas y no efectos, centrarse en el nivel de la palabra y no el pragmático o contextual, ignorar el proceso comunicativo o estar basadas en valores absolutos (compartimentos estancos) intentaremos subsanarlas con nuestra propuesta tipológica, teniendo en cuenta todos esos aspectos.

\subsubsection{Desde la Comunicación Intercultural: las habilidades cognitivas del intermediario}

En la definición de términos culturales de una civilización tan alejada como la japonesa, uno de los principales problemas consiste en la correcta interpretación del contexto sociocultural y en su adecuado traslado al lector de la cultura meta. En palabras de Nida (1990, p.1): «Los errores más grandes en traducción e interpretación no resultan normalmente de una insuficiencia de palabras, sino de la falta de suposiciones culturales correctas». Según Vermeer (1992), que defendió en toda su obra la traducción como un «acto transcultural», el traductor debe anticiparse a lo que el destinatario sabe o no sabe - la base de sus suposiciones culturales - para modular su texto de manera que sea comprensible. Surgen de este modo diferentes estrategias que explican por qué algunos diccionarios de lenguas europeas consideran conveniente especificar las diferentes maneras de beber el sake (como se comprueba en Fernández Mata, 2016) pero no las del whisky. Creemos que ahí se aprecia la acción de un intermediario cultural que ha querido tener en cuenta las suposiciones y conocimientos previos de cada cultura para poder facilitar la comunicación.

Es lo que Pym (1995) denomina en alemán Blendlinge, un «mestizo / híbrido» que pertenece a dos culturas y tiene la obligación, en tanto agente mediador, de actuar en beneficio de las dos partes. Numerosos teóricos como Taft o Bennett se han referido a esta necesaria «biculturalidad» del traductor como intermediario, mientras que otros como Hatim \& Mason o Baker han destacado la forma en que cada uno proyecta sus conocimientos y creencias 
al producir un texto (Katan, 2009). Es aquí donde aparecen los sesgos interpretativos; psicólogos sociales como Allport (1954), en sus estudios sobre los prejuicios como procesos cognitivos, se han referido a la manera en que estos condicionan nuestra percepción de otras culturas - etnias - con base en determinados estereotipos que heredamos de nuestra cultura nativa y que son casi imposibles de eliminar. Como manifestó el antropólogo LéviStrauss (2011, pp. 171-172) en una conferencia dictada en Tokio en 1986, los seres humanos crecemos con un «sistema de referencias» impreso en nuestra mente por el entorno familiar y social con el que nos conducimos toda nuestra vida, de manera que solo somos capaces de percibir los sistemas de otras culturas «a través de las deformaciones que nuestro propio sistema les inflige».

Creemos que esas deformaciones suelen estar influidas por varios tipos de sesgo (que no se limitan a un mero desconocimiento cultural): prejuicios y estereotipos sobre los miembros de determinada cultura, la influencia de la cultura propia mezclada con una visión distorsionada de culturas consideradas exóticas, la tendencia a sobredimensionar los elementos que más nos llaman la atención, etc. De ahí provienen mitos como el de que los obreros japoneses reivindican sus derechos trabajando más horas para crear excedentes a la empresa sin necesidad de faltar a sus obligaciones laborales ni renunciar a su salario (las famosas «huelgas a la japonesa»), malentendidos como el de que las geishas son intrínsecamente prostitutas, o definiciones como la que la RAE (2014) hace de sumo destacando erróneamente que el peso de los contendientes «excede siempre de los $100 \mathrm{~kg}$ », debido quizás a la imagen popular de «combate de gordos» (en realidad no existen requisitos de peso mínimo). Trataremos de elucidar las causas concretas de cada error de interpretación cultural, aunque por necesidad esta será la parte menos objetiva de nuestro estudio.

\section{Análisis de problemas: tipología y descripción}

Antes de centrarnos en las categorías de problemas semántico-pragmáticos correspondientes a las tres perspectivas de nuestro marco teórico, hemos incluido un breve apartado destinado a categorizar los principales errores de tipo fonológico, morfosintáctico, de escritura / lectura y lexicográfico.

\subsection{Erratas y errores relacionados con el sistema lingüístico japonés}

\subsubsection{Nivel fonológico y de lectoescritura}

Al margen de erratas tipográficas, entre los errores más frecuentes encontramos algunos cambios vocálicos arbitrarios (*komari [ $\leftarrow$ komori] uta) que han producido una conversión a sinogramas incorrecta (*小毬 [ 子守] 唄). En relación con el cambio fonológico, vemos metátesis muy frecuentes del tipo «*komodo [ $\leftarrow$ kodomo] manga». En otro plano diferente encontramos errores causados por distintos kanji con una misma lectura (debakame: *出刃 亀 [ 出歯亀]) o por un mismo kanji con diferentes lecturas (秋田犬: Akita *ken [ $\leftarrow$ inu]). La medida de longitud (3,03 m) usada sobre todo en textiles y conocida como jō (丈) ha sido transcrita con el homófono 畳, una medida de superficie equivalente a una estera de tatami. Son todos errores muy comunes fruto de confusiones, descuidos o mero desconocimiento. 


\subsubsection{Nivel morfosintáctico y lexicográfico}

En primer lugar, debido al empeño de adscribir cada sustantivo a un único género gramatical según criterios más o menos subjetivos (pp. 26-27), se ha contravenido el uso establecido por los hablantes y por la lógica en numerosos casos; p.ej. «la yakiniku», por el uso del hiperónimo carne en la definición, a pesar de que se refiere más bien a un plato o estilo de cocina y es muy utilizado también como masculino; este fenómeno lo observaremos en muchos de los ejemplos analizados más adelante: (2) «la tsukisoi» por limitarlo a mujeres, (10) «la tankōbon» por confundirlo con una revista; (27) «la ganbare» por entenderlo como una exhortación, etc.

En otro tipo de problemas encontramos la lexicalización de adjetivos como sustantivos (el jōhin: «Refinamiento; elegancia»), verbos o sustantivos de acción referidos a la persona que los realiza (el takuhatsu como un «monje [que mendiga]») e incluso nombres propios tratados casi como si fueran comunes genéricos (el gojira: «Monstruo de una película; un mutante de la bomba atómica» [ $=$ Godzilla $]$ ).

El tratamiento incoherente del prefijo honorífico $o$ - ha dado lugar tanto a envíos (ofuro $\rightarrow$ furo) como a lexicalizaciones por separado (mamori / omamori), algunas incluso con una distinción semántica errónea (cha: «Té» / ocha: «Té verde»).

En una última tipología relacionada con un posible error de comprensión de estructuras morfosintácticas en el análisis de corpus, encontramos casos como el de senpai kōhai, que en lugar de recogerse por separado cada uno con su definición, se lexicaliza como un único término, de género femenino («Relación informal $[\ldots] »){ }^{3}$

\subsection{Problemas analizables desde las teorías sobre el cambio semántico}

\subsubsection{Restricción de significado}

Se considera que ha ocurrido una «restricción de significado» cuando una palabra pasa a referirse solamente a una parte específica de todos los objetos o conceptos que antes designaba. En los procesos diacrónicos de cambio semántico suele producirse por una especialización del uso: p.ej., en inglés corn pasó de significar «cereal» a «maíz» en Inglaterra o «avena» en Escocia (Grzega \& Schöner, 2007, p.30). En el caso de los préstamos, este fenómeno es palpable en el uso de términos como sake, katana, origami o manga referidos exclusivamente a la cultura japonesa, aunque en su idioma original también quieran decir «bebida alcohólica», «sable», «papiroflexia» y «cómic», en general. En nuestro caso de estudio, observamos que el problema se produce cuando una definición introduce arbitrariamente restricciones semánticas, mediante diferencias específicas que no se corresponden con la realidad (1) (2), mención limitada de características (3), o elección inapropiada de vocabulario (4).

(1) Gohonzon 御本尊 /el/ Objeto de devoción de la escuela budista Soka Gakkai; representación física del ideal de budeidad. [p.84] ${ }^{4}$

En japonés llamamos honzon o Gohonzon - con prefijo honorífico- al objeto principal de culto de cualquier templo budista o casa: una figura de un buda o bodisatva, una caligrafía con su nombre, una imagen, un mandala, etc. En esta definición, sin embargo, se lexicaliza el término en fuerte relación con Soka Gakkai, organización que en realidad adopta el mismo Gohonzon (un pergamino con el título del Sutra del Loto como eje) que las distintas ramas 
de la Escuela Ortodoxa Nichiren de la que fue expulsada en 1991. Se produce pues una importante reducción del área semántica del término, al quedar aparentemente excluidas todas las demás ramas budistas.

(2) tsukisoi 付き添い/la/ Asistente de cabecera, generalmente una mujer, que cuida a un paciente hospitalizado. [p.270]

Esta palabra se refiere tanto a la acción como a la persona (tsukisoinin) que acompaña, asiste o cuida a otra: sin distinción de sexo, puede ser alguien que vigila a un niño, un padre que acompaña a su hijo a la graduación, un padrino de boda, una dama de honor, la pareja de un invitado, los portadores del féretro en un funeral... La definición aquí ofrecida está muy limitada y parece basarse en una única ocurrencia textual.

(3) fumie 踏絵 /la/ En la Era Edo (1600-1868), bandeja con un crucifijo o imagen cristiana que había que pisar como demostración de apostasía; prueba de lealtad. [p.75]

Numerosas obras documentales y de ficción han dado cuenta, ya desde el siglo XVIII, de la existencia del fumie durante la persecución de los cristianos. Aunque el uso representado más común suele ser el de algún sacerdote que renuncia a su fe $-\mathrm{o}$ lo finge—, la mayoría de japoneses y los europeos protestantes que pisaban el fumie no lo hacían para apostatar sino para demostrar a las autoridades que no eran católicos. Este segundo uso ha quedado eliminado de la definición.

(4) takidashi 炊き出し/el/ Reparto de arroz hervido. // Hubo un takidashi en favor de las víctimas del terremoto. [p.258]

Si bien el significado literal y primigenio («cocer y servir») se refiere al arroz blanco, que es el alimento base en Japón, hace mucho tiempo que un takidashi es, por obra de sinécdoque, un reparto de comestibles en general a los afectados por una catástrofe. La interpretación literal del término ignora la ampliación de significado producida en el seno de la lengua original para reducirlo de nuevo al incorporarlo a la nuestra.

\subsubsection{Ampliación de significado}

Se considera que ha ocurrido una «ampliación de significado» (también extensión o generalización) cuando el área semántica de una palabra se ha ensanchado hasta abarcar elementos que antes quedaban fuera. En los procesos diacrónicos de cambio semántico, es común que se produzca por motivos de metáfora, similitud o contagio: p.ej., meshi / gohan en el sentido de «comida» y no solamente «arroz». En el caso de los préstamos, encontramos términos como hentai, que en español ha cambiado su sentido original de «pervertido / degenerado» por el más amplio de «erótico»o «pornográfico» (como género de manga o animación). En nuestro caso de estudio, el problema se produce cuando una definición incompleta elimina ciertas restricciones semánticas, dando lugar a un grado más alto de abstracción y fracasando en transmitir el significado preciso del término. 
(5) oya 大家 /el, la/ Propietario de una vivienda. [p.208]

Mientras que en japonés quiere decir «casero», en referencia al arrendador respecto del inquilino, aquí se ha lexicalizado como si significara cualquier propietario.

(6) satogaeri 里帰り/la/ Visita a la casa de los padres [p.223]

Se obvia el significado original («regreso al pueblo natal», casi siempre quedándose en la casa familiar durante varios días de vacaciones) y se amplía a cualquier visita a la casa de los padres, aunque vivan en el mismo barrio y se los visite unos minutos.

(7) yonkoma 四コマ/el/ Historia de manga con frecuentes situaciones absurdas. // Shin-chan es un popular personaje de yonkoma. [p.287]

Las historietas yonkoma («cuatro viñetas») se asemejan a las famosas tiras cómicas que también se publican en la prensa occidental. Aunque suelen incluir situaciones cotidianas disparatadas, el término hace referencia al formato más que al género. Se ha producido una extensión que abarcaría todo tipo de obras con humor absurdo.

\subsubsection{Sustitución de significantes}

En correspondencia con la «transferencia de significados» del cambio semántico, proponemos esta tercera categoría en la que algunos significantes no han ampliado ni reducido su significado, sino que han suplantado por equivocación el de otro término similar o próximo. Esto ha ocurrido ya con la lexicalización de tatami exclusivamente como «tapiz acolchado sobre el que se ejecutan algunos deportes, como el yudo o el kárate» (RAE, 2014), en sustitución de su significado original como estera de paja que sirve de suelo. Destacamos cinco voces de las que la mayoría guardan semejanza formal o proximidad de significado con el concepto suplantado; en las dos últimas, además, apreciamos una confusión entre términos históricos antiguos y modernos.

(8) okurigana 送り仮名 /la/ Letra kana añadida a un sinograma para indicar la lectura en japonés. [p.201]

Esta escueta definición parece más bien la de furigana. El okurigana es la parte posterior de una palabra que se escribe en kana porque no está incluida en la pronunciación del kanji. Es omnipresente en verbos y en adjetivos tipo -i, donde incluye siempre la desinencia o morfema flexivo y a veces parte de la raíz.

(9) bakeneko 化け猫 /el/ Figura en forma de gato que levanta sin cesar la pata delantera izquierda para atraer buena suerte. [p.47]

La definición corresponde al término manekineko (aunque la explicación sobre la pata es inexacta). Bakeneko es un tipo de yōkai (monstruo o ser sobrenatural del folclore japonés): un gato que puede suplantar la identidad de un humano tras devorarlo. 
(10) tankōbon /la/ Revista semanal o mensual recopilatoria de manga. [p.260]

Este término de la industria editorial designa una publicación en forma de libro o tomo editado monográficamente; por ejemplo, cada uno de los volúmenes numerados en que se va recopilando toda una serie de manga, previamente publicada capítulo a capítulo junto a otras series en las revistas especializadas que aquí se mencionan por error.

(11) Kyōto shugo 京都守護 /el/ Gobernador militar de Kioto, puesto creado en 1862. [p.162]

El cargo que corresponde a la definición es otro: Kyōto-shugoshoku (abolido en 1867). El puesto de Kyōto-shugo existió en 1185-1221 durante el periodo Kamakura.

(12) dajōkan 太政官 /el/ "Gran Consejo de Estado": en el Japón antiguo, el órgano administrativo central del Gobierno. [p.62]

La definición corresponde a Daijōkan, pues la lectura Dajōkan de esos mismos kanji suele reservarse a la institución correspondiente de principios de Meiji (1868-1885).

\subsubsection{Creación léxica por etimología popular}

Los procesos de cambio lingüístico por etimología popular o «reanálisis morfológico» son un tipo de etimología falsa basada en la interpretación fantasiosa que hacen los hablantes de ciertos elementos fonológicos o morfosintácticos de una palabra. Aunque Grzega (2003, p.32) apunta que «las adaptaciones por etimología popular no suelen ser provocadas por quien introduce el préstamo para nombrar la cosa, sino por la comunidad de hablantes, que posteriormente trata de adoptar la palabra», hay casos en que son los propios impulsores del préstamo los que cometen el error.

(13) sutra すとら 経 /el, la/ Texto del budismo que expone enseñanzas relativas a las diferentes vías de conocimiento para alcanzar la iluminación. [p.254]

Atribuir la palabra de origen sánscrito sūtra a un kanji japonés ([o]-kyō), incluso transcribiéndola al hiragana, es una confusión garrafal. Además, aunque en japonés existan formas alternativas como sūtora en katakana (スートラ) o incluso shutara en kanji (修多羅), en ningún caso la voz española «sutra» es un japonesismo.

(14) ninja [ninjo] 忍者 [忍女] /el, la/ Agente secreto, hombre [ninja] o mujer [ $\underline{\text { ninjo }}$ ], del Japón premoderno diestro en el sigilo y secreto de sus intervenciones; ninja. [p.190]

Formada por nin («esconderse») y ja («persona»), la palabra ninja se refiere a un tipo de agente secreto experto en espiar y confundir al enemigo con disfraces, rumores falsos, etc. (la imagen de guerreros ninja que tenemos en Occidente pertenece al ámbito de la ficción y es muy posterior). El error de esta entrada está en la versión femenina aparentemente inventada, en que se ha sustituido el kanji de «persona» por el de «mujer». No hemos 
encontrado ninguna ocurrencia de esta forma léxica con ese significado: su sentido correcto —leído como shinobi onna - es el de «amante» o «prostituta», mientras que las mujeres ninja son conocidas, desde hace pocas décadas y gracias al mundo de la ficción, como kunoichi (por semejanza con el orden en que se escriben los trazos del sinograma de «mujer»).

\subsection{Problemas analizables desde la traductología}

\subsubsection{Error por exceso de literalidad}

Pensamos que se produce cuando un enfoque demasiado superficial del texto da lugar a malas traducciones literales, interpretaciones al pie de la letra que no profundizan en el sentido de los conceptos, traslaciones erróneas de cognados en inglés (que además ponen de manifiesto la dependencia de la bibliografía en este idioma), etc.

(15) kokutai 国体 /la/ "Política nacional": sistema de Estado en términos de la sede de la soberanía nacional. / "National polity" [...] [p.152]

Si bien no es fácil traducir y definir lo que designa el término kokutai, turbio concepto que fue argumentado y reinterpretado en cada época sucesiva en la que estuvo vigente, tampoco podemos considerar adecuado que se traduzca mal del inglés (aquí polity es «forma / estructura de gobierno», «entidad políticamente constituida», etc.) ni que la definición sea una escueta paráfrasis. El kokutai («modelo de Estado» en su sentido más filosófico y político, «esencia nacional» en el más identitario y religioso) consistió sobre todo en una concepción exclusivista de la nación japonesa, singular e inmutable, como un país sagrado y protegido por los dioses, regido y gobernado por el Tennō («emperador celestial»), patriarca de la gran familia japonesa, poseedora esta de valores morales supremos como el patriotismo, la lealtad o la piedad filial.

(16) Narita rikon 成田離婚 /el/ "Divorcio en Narita": divorcio realizado al volver del viaje de bodas en el aeropuerto de Narita. / [...] divorce carried out at the Narita airport [...] [p.186]

La definición resulta disparatada al obviarse el carácter metafórico de esta locución jocosa (y algo trasnochada). Si bien los recién casados deciden divorciarse tras algún desengaño mutuo durante la luna de miel en el entorno adverso de un país extranjero, obviamente no tramitan la ruptura matrimonial en el mismísimo aeropuerto.

\subsubsection{Error de adecuación semántica}

Se produce cuando el sentido o la combinación de sentidos de la traducción no logran transmitir el concepto representado en la palabra o expresión original.

(17) murishinjū 無理心中 /el/ Suicidio obligado. [p.180]

Un shinjū es en origen un suicidio doble de dos enamorados por mutuo acuerdo (tema literario recurrente desde tiempos de Chikamatsu Monzaemon, 1653-1725). También puede referirse a un suicidio acordado por personas relacionadas entre sí, como un padre y un hijo o una familia entera. Al añadirle muri («por la fuerza») se convierte en el típico caso criminal 
en que un suicida voluntario asesina primero a algún allegado. Ninguna de estas muertes se corresponde con lo que entendemos en castellano como «suicidio obligado» (por ejemplo, algunas condenas a muerte por harakiri o seppuku).

\subsubsection{Error de adecuación pragmática}

No son pocas las expresiones japonesas que carecen de equivalente exacto en otras lenguas y deben ser traducidas según el concepto de equivalencia dinámica o funcional, existiendo diferentes posibilidades según la función que desempeñen en cada contexto comunicativo. Sin embargo, esas opciones de traducción no son un «equivalente» absoluto que deba o pueda ser lexicalizado en un diccionario académico. Los dos lemas siguientes, en lugar de ser explicados con precisión, han sido traducidos por una única equivalencia que correspondería a una ocurrencia singular en un contexto determinado, obviando el sentido global de la expresión y su importantísima intención ilocutiva. Se trata de errores graves, de principiante.

(18) sumimasen /el/ "Perdón": la forma más común de disculpa verbal en lengua japonesa. // En una sociedad como la japonesa en donde tan importante es la armonía social, se oye mucho la palabra sumimasen. [p.252]

A juzgar por esta definición, pareciera por ejemplo que los clientes de los restaurantes japoneses tengan por costumbre gritar perdón al aire mientras comen y beben. Esto es porque no se han recogido otros usos como el de llamar la atención de alguien con educación (ni siquiera la traducción inglesa ofrece la opción «Excuse me» aparte del consabido «Sorry») o dar las gracias con determinado matiz.

(19) yoroshiku 宜し</el/ Fórmula de cortesía cuando uno es presentado: "encantado de conocerlo". [p.288]

Así, con una explicación simplona que no se corresponde para nada con el sentido y el uso originales, queda despachada una de las expresiones más versátiles de la lengua japonesa, imprescindible para comprender la psicología social de sus hablantes. En contra de la obligada función lexicográfica y didáctica de un diccionario, no se ofrece una definición - por breve que sea - que ayude a quien lo consulta a comprender la expresión en sí misma, sino la ya trillada fórmula sustitutoria con la que se traduce para salir del paso en una sola de las situaciones posibles (y no la más importante).

\subsubsection{Error de adecuación contextual}

Se produce al traducir una palabra o elaborar la definición del concepto designado sin alcanzar a explicar sus características contextuales esenciales, dejando al lector a ciegas sobre el uso y el sentido global del término.

(20) ipponjime 一本締め/el/ Aplauso de todos $10[\mathrm{~s}]$ asistentes a una reunión y que sigue este modelo: tres veces tres palmadas y una palmada final. [p.108]

De poco sirve esta explicación si no se especifica que los aplausos se ejecutan al final, a modo de pequeño ritual de fin de fiesta, para celebrar que se ha alcanzado un acuerdo o que simplemente ha terminado todo bien y puede disolverse la reunión. 
(21) shakaijin 社会人 /el, la/ Persona socialmente competente. [p.229]

Estas tres palabras son más bien una traducción libre — a la par que ambigua - que podría utilizarse en una novela, dependiendo del contexto en que apareciera, pero no son una definición correcta. Se suele entender por shakaijin («persona de la sociedad») alguien que ha entrado en el mercado laboral tras sus años como estudiante y es un miembro productivo de la comunidad, una pieza más del engranaje social que mueve el país; algunos lo interpretan simplemente como «adulto», aunque no tenga un empleo regular (ancianos, amas de casa...), pero no hay unanimidad.

\subsubsection{Error de adecuación factual}

En contraste con los casos anteriores, el elemento al que no se adecúa la definición se encuentra totalmente fuera del lenguaje, en realidades objetivamente contrastables que no son susceptibles de interpretación semántica, pragmática o contextual.

(22) hensachi 偏差值 /el/ Sistema educativo por el cual solo se juzga el progreso del estudiante por las notas académicas. [p.95]

El hensachi («valor de desviación») es la puntuación relativa que se obtiene en un examen en relación con la nota media del grupo y la desviación típica. Así, por ejemplo, al ser la fórmula utilizada para valorar las pruebas de acceso a la universidad, puede referirse tanto a la calificación particular de un aspirante como a la «nota de corte» de una carrera. En ningún caso se trata de un «sistema educativo».

(23) shōchū 焼酎 /el/ Aguardiente destilado de batatas, arroz, mijo, etc. // Legalmente el contenido alcohólico del shōchū no debe pasar de $36^{\circ}$, pero a veces llega a los $45^{\circ}$. [p.241]

Sorprende esta inadmisible explicación que sugiere una campante ilegalidad. Lo cierto es que la Ley de impuesto sobre el alcohol (Shuzeihō) permite desde 1953 un límite de $35^{\circ}$ para el shōchū elaborado por destilación fraccionada (el que se usa para chūhai o umeshu) y otro de $45^{\circ}$ para la simple (apodado «shōchū auténtico»).

\subsubsection{Error de coherencia intertextual}

Cuando trasladamos a una lengua la terminología de otra, especialmente los nombres propios, es importante consultar la traducción establecida en lugar de inventar una propia, para mantener la coherencia intertextual dentro de la cultura de llegada.

(24) kunaichō 宮内庁/la/ Agencia de la Familia Imperial. [p.158]

«Agencia de la Casa Imperial» es la fórmula preferida por la Embajada de Japón en España, la Casa de S. M. el Rey, la Casa Asia de Barcelona y los textos oficiales, académicos y periodísticos. La traducción aquí ofrecida apenas la hemos encontrado en una decena de 
páginas web personales. Apreciamos en esta ausencia de cotejo una falta de rigor e incluso de delicadeza hacia la institución.

\subsection{Problemas relacionados con la comunicación intercultural}

\subsubsection{Mito de la "palabra intraducible»}

Hemos denominado así la tendencia que tenemos a creer en la supuesta naturaleza única de algunos términos extranjeros que vemos como «intraducibles», con matices conceptuales atípicos, aunque sean voces comunes con equivalentes en otras lenguas.

(25) konketsuji 混血牢 /el, la/ Persona mestiza, casi siempre referida al individuo de padre o madre de Japón, y de padre o madre de raza blanca o negra. [p.153]

Esta voz (literalmente «niño de sangre mezclada») no denota una etnia, cultura o nacionalidad específica de uno de los progenitores tal como se afirma (ni siquiera «casi siempre»), por lo menos no más que las expresiones análogas en otras lenguas cuando se usan en sus respectivas sociedades. No nos encontramos, por tanto, ante un concepto específico de la cultura japonesa que merezca ser importado y lexicalizado.

\subsubsection{Confusión de ficción y realidad}

En ocasiones el concepto importado se corresponde con ciertas representaciones fabulosas del mundo de la ficción que nos han llegado por esa vía, y no con la realidad histórica (como en el caso de los «guerreros ninja»).

(26) obasute 姨捨 /el/ “Abandono de ancianas”: en el Japón premoderno, la acción de abandonar generalmente en el monte a los ancianos de familias campesinas muy pobres. // La película titulada La balada de Narayama, de 1958, reveló a muchos occidentales la costumbre del obasute. [p.195]

Calificar de «costumbre» del «Japón premoderno» (hasta 1868) lo que es una mera leyenda anterior al siglo $\mathrm{X}$ recogida y adaptada en obras posteriores parece una clara confusión agravada por la influencia del célebre filme de 1958 y su remake de 1983. El antropólogo Jun Katata (1984) explica que el «abandono de ancianos» (rōjin iki) entre los esquimales y en algunas culturas indígenas de Bolivia, Escandinavia, África o Australia, al igual que en Japón, tiene más de mito literario que de realidad histórica. En este país, la «leyenda del monte Obasute» (en la actual Nagano) es en realidad una fábula donde la obligación de abandonar a los ancianos, impuesta por un ficticio señor feudal, deriva en una moraleja sobre su bondad y utilidad social.

\subsubsection{Sesgo por influencia de estereotipos culturales}

Hemos detectado la posible influencia de estereotipos que a pesar de contener algo de verdad condicionan demasiado la visión que tenemos de Japón y han dominado los estudios culturales japoneses desde finales de la segunda guerra mundial (27) (28), clichés sobre la personalidad de los japoneses (29) y tópicos sobre elementos importados (30) (31). En este primer estudio hemos evitado establecer subcategorías. 
(27) ganbare 頑張れ /la/ Exhortación al trabajo duro y al esfuerzo dirigidos a alcanzar un objetivo grupal. [p.79]

Esta forma imperativa del verbo ganbaru («llevar las ideas o intenciones de uno hasta el final a pesar de las dificultades») es similar a la interjección española «jánimo!» con que alentamos a alguien para que ponga empeño. La última palabra de la definición es cosecha propia de algún intermediario cultural, y solo se explica desde una visión prejuiciosa centrada en el predominio de la «mentalidad de grupo», el principal estereotipo sobre la cultura japonesa en el último siglo (Hirai, 2000).

\section{(28) girininjō 義理人情 /el/ Conflicto entre el deber y los sentimientos. [p.83]}

Desde los primeros misioneros europeos que llegaron a Japón hasta Ruth Benedict en su famoso ensayo El crisantemo y la espada (1946), se ha querido ver la cultura japonesa como un conflicto dualista entre fuerzas opuestas (Kawasaki, 1955). Aunque el giri y el ninjō son dos conceptos independientes que a menudo entran en conflicto, no pueden lexicalizarse como tal porque también existe otra visión menos maniquea en la que el sentido del deber social y la empatía personal se combinan como virtudes complementarias de una misma persona: Es un hombre de sólido girininjō.

(29) dogeza 土下座 /la/ Postración tocando el suelo con las manos y las rodillas. // Cuando entramos en su casa, su padre nos dio la bienvenida haciendo una dogeza. [p.64]

La dogeza no es una muestra de bienvenida sino de humillación, de arrepentimiento o petición de perdón o favores en situaciones muy extremas, con la cabeza mirando al suelo. La imagen descrita en la frase de uso no se corresponde con la realidad; incluso aunque pretendiera ser un ejemplo de alguna obra literaria ambientada en la sociedad jerárquica de Edo, ni es representativo ni está contextualizado. Parece más bien fruto de la fantasía o imaginación de alguien que se ha dejado llevar por sus desafortunados estereotipos sobre los aparatosos modales japoneses.

(30) sushi 寿司 /el/ Lonchas de pescado crudo sobre arroz suavemente avinagrado. [p.253]

(31) bishōjo, bishōnen 美少女，美少年/el/ Subgénero de manga con abundancia de escenas violentas. [p.49]

$\mathrm{Ni}$ el sushi es solo pescado crudo ni los mangas protagonizados por personajes juveniles atractivos se definen por su violencia (ningún género específico de manga lo hace). Esta identificación exclusiva del sushi con el ingrediente que más nos llama la atención a los occidentales y del manga con el manido prejuicio occidental de la violencia japonesa fue uno de los errores cometidos por la RAE al recoger por primera vez ambos términos en su diccionario en línea en junio de 2012. En ambos casos primaba una percepción parcial o sesgada de la sociedad de origen centrada en una mirada muy peculiar desde la sociedad 
receptora. ${ }^{5}$ Tras las quejas de algunos profesionales, la RAE decidió cambiar las definiciones por otras algo más ajustadas a la realidad; resulta particularmente grave que un diccionario académico especializado en cultura japonesa resucite cuatro años después aquellos errores ya subsanados.

\subsubsection{Interferencia de patrones culturales propios}

Ocurre cuando percibimos un concepto extranjero desde el prisma de nuestro propio sistema cultural y sus presuposiciones interpretativas.

(32) Shūmon aratame 宗門改め /la/ Institución de la Era Edo (1600-1868) destinada a extirpar el cristianismo de suelo japonés. [p.246]

A pesar de haber sido citado como «la Inquisición japonesa» en numerosas obras occidentales por analogía con ese tribunal español, no podemos dejar que la paráfrasis nos impida una correcta comprensión del fenómeno: supuso una serie de medidas políticas y religiosas que derivaron en un sistema censal de creyentes, ejecutadas por el shogunato a través de magistrados. Pero nunca fue una «institución».

\section{Análisis final y propuesta de soluciones}

Como hemos podido comprobar a lo largo del análisis, la intención de la tipología que proponemos no es clasificar o delimitar diferentes tipos de errores con categorías cerradas y mutuamente exclusivas, sino presentar los problemas más frecuentes desde diferentes perspectivas teóricas, con algunos ejemplos que también podrían clasificarse de otra manera. Por ejemplo, en el caso de sumimasen advertimos un error de traducción (falta de adecuación a todos sus posibles valores pragmáticos) influido por un probable estereotipo sobre los japoneses (expresiones de disculpa constantes), que a su vez resulta en cambio semántico (reducción de significado).

Las fronteras entre las diferentes categorías son por tanto tenues y flexibles; se podrían introducir otros matices y distinciones. Además, apreciamos una especie de correlación según la cual los errores lexicográficos han absorbido algún caso que procede de los mecanismos de cambio lingüístico, los cambios semánticos a su vez acaparan problemas que procederían de los errores de traducción (sentidos restringidos, ampliados o emparentados según la terminología de Palazuelos et al., 1992), mientras que estos por su parte se deben a menudo a malentendidos culturales.

En sentido inverso, los problemas de comunicación intercultural suelen estar relacionados con las causas del error (desconocimiento, prejuicios...), mientras que las categorías de errores de traducción contienen casos que pueden analizarse desde las causas (mala documentación, falta de habilidades pragmáticas...) o desde el resultado (al comparar con la definición original); por último, los problemas analizables desde las teorías sobre el cambio lingüístico son casi todos evaluables desde las consecuencias (pérdida, ganancia o intercambio de significado).

Esta borrosa imprecisión en categorías contiguas - fuzziness - no es relevante porque la finalidad de nuestra tipología de problemas es poder contar con una guía de referencia que nos sirva para tomar medidas y evitar futuros errores. Trabajar con mejores fuentes documentales (a ser posible en japonés), no dejarse influir por la cultura propia o las ideas preconcebidas, huir de los mitos, comprobar y corroborar, consultar textos paralelos, tener 
siempre en mente al receptor del mensaje para poder transmitir adecuadamente los matices, tratar de no confundir unos términos con otros y no añadir ni eliminar ninguna información que pueda alterar el significado son algunas de las soluciones que podemos aplicar, si las condiciones psicológicas y de trabajo lo permiten. En último lugar, habrá que revisar posibles fallos y erratas.

Proponemos, entonces, un proceso de comprobación en cuatro fases (Tabla 1) que se corresponden, en orden inverso, con los cuatro tipos de categorías establecidos en este estudio; cada una de las fases va enfocada a evitar los diferentes problemas encontrados desde las tres disciplinas aplicadas: comunicación intercultural, traductología y lingüística -cambio semántico y sistema lingüístico japonés.

Tabla 1. Tipología de problemas en el proceso de lexicalización de japonesismos en español.

\begin{tabular}{|c|c|c|c|}
\hline FASE & OBJETIVOS & CATEGORÍAS DE PROBLEMAS A EVITAR & EJEMPLOS \\
\hline 1. & $\begin{array}{c}\text { Comprender correctamente la cultura } \\
\text { original } \\
\text { (comunicación intercultural) }\end{array}$ & $\begin{array}{l}\text { (1) Mito de la "palabra intraducible» } \\
\text { (2) Confusión de ficción y realidad } \\
\text { (3) Influencia de estereotipos culturales } \\
\text { (4) Interferencia de la cultura propia }\end{array}$ & $\begin{array}{l}\text { konketsuji } \\
\text { obasute } \\
\text { sushi } \\
\text { Shūmon aratame }\end{array}$ \\
\hline 2. & $\begin{array}{l}\text { Transmitir fielmente el sentido } \\
\text { mediante traducciones o explicaciones } \\
\text { aptas para el destinatario } \\
\text { (traductología) }\end{array}$ & $\begin{array}{l}\text { (1) Errores por exceso de literalidad } \\
\text { (2) Errores de adecuación semántica } \\
\text { (3) Errores de adecuación pragmática } \\
\text { (4) Errores de adecuación contextual } \\
\text { (5) Errores de adecuación factual } \\
\text { (6) Errores de coherencia intertextual }\end{array}$ & $\begin{array}{l}\text { Narita rikon } \\
\text { murishinjū } \\
\text { yoroshiku } \\
\text { shakaijin } \\
\text { shōchū } \\
\text { kunaichō }\end{array}$ \\
\hline 3. & $\begin{array}{c}\text { Lexicalizar el término con corrección y } \\
\text { precisión } \\
\text { (cambio semántico) }\end{array}$ & $\begin{array}{l}\text { (1) Restricciones de significado } \\
\text { (2) Ampliaciones de significado } \\
\text { (3) Sustitución de significantes } \\
\text { (4) Etimologías populares }\end{array}$ & $\begin{array}{l}\text { Gohonzon } \\
\text { òya } \\
\text { tankōbon } \\
\text { ninjo }\end{array}$ \\
\hline 4. & $\begin{array}{l}\text { Eliminar erratas y errores } \\
\text { (sistema lingüístico japonés) }\end{array}$ & $\begin{array}{l}\text { (1) Nivel fonológico y de lectoescritura } \\
\text { (2) Nivel morfosintáctico }\end{array}$ & $\begin{array}{l}\text { komodo/Akita ken } \\
\text { senpai kōhai }\end{array}$ \\
\hline
\end{tabular}

\section{Conclusiones y perspectivas}

Como dijo el maestro de la antropología cognitiva y marítima Charles O. Frake (1980), las diferentes culturas son como distintas escuelas de navegación que nos permiten afrontar diferentes mares; no obstante, cuando incorporamos términos de otra cultura a menudo lo hacemos para adaptarlos a nuestro propio sistema de navegación. Es normal, pues, que reformulemos algunos conceptos a nuestra manera, alterando su significado o inventando matices que no existen en la cultura de origen porque nosotros los percibimos así. Sin embargo, la función principal de incorporar a nuestro léxico marcadores culturales propios de otra civilización es poder surcar en sus aguas o, al menos, comprender sus vaivenes.

Por ello, la aparición de nuevas obras de referencia sobre Japón a disposición del público hispanohablante debe ser considerada una buena noticia; no obstante, en casos como el que hemos estudiado, la inesperada abundancia y repetición de errores graves en un mismo trabajo, impulsado por autoridades académicas y refrendado por instituciones oficiales, puede terminar por crear y perpetuar más problemas de comprensión cultural que aquellos que pretende resolver. Esperamos que el aporte cualitativo que debe suponer este trabajo desde el punto de vista del análisis semántico de japonesismos incorporados al español pueda contribuir a una mejora de las prácticas investigadoras, pedagógicas, divulgativas o de traducción, ayudando a evitar errores que nos distancian de una comprensión profunda de la civilización japonesa y nos alejan, en consecuencia, de un entendimiento mutuo auténtico y mejor. 
Asimismo, serán necesarios en el mundo hispanohablante ulteriores trabajos que nos acerquen como comunidad cultural a un conocimiento más profundo de la realidad japonesa a través de la idiosincrasia patente en su vocabulario. Tras este primer análisis sobre la naturaleza de los problemas más comunes en la introducción deliberada [directa] de términos culturales japoneses, se debería avanzar hacia otro tipo de análisis centrados en la introducción espontánea [indirecta] mediante textos académicos, divulgativos, periodísticos, literarios e incluso informales de nuestro idioma. También aspiramos a una progresión del análisis cualitativo al cuantitativo y a una mejora del exiguo sistema de categorías que hemos propuesto. De la precisión y el rigor con que asimilemos el vocabulario de otra cultura, embarcados como estamos en un intento sincero de comprenderla, dependerá el éxito de nuestra travesía.

\section{Notas}

1. Los autores son el Dr. James Flath, profesor de filología inglesa en la Universidad Complutense de Madrid; Ana Orenga, correctora editorial y antigua profesora de español en el Instituto Cervantes; el Dr. Carlos Rubio, profesor, autor y traductor experto en literatura japonesa, condecorado con la Orden del Sol Naciente por su divulgación de la cultura de Japón; y el Dr. Hiroto Ueda, profesor de español en la Universidad de Tokio y miembro correspondiente extranjero de la RAE.

2. Algunas voces cuyo origen japonés muchos hablantes ya no reconocen, como «soja»o «biombo», son excepcionales en el sentido de que fueron introducidas en estadios muy tempranos (siglos XVI-XVIII), algunas desde el portugués.

3. Suponemos que se ha extraído el lema de alguna ocurrencia del tipo «la relación senpaikōhai», interpretando el término como significante de la relación en sí y no como las dos partes separadas de ella (cf. «la relación profesor-alumno»).

4. Por motivos de espacio, salvo en casos necesarios hemos omitido la escritura en hiragana, la abreviatura de ámbito léxico, la definición en lengua inglesa y la frase modular o de uso que se añade en contadas ocasiones. Hemos subrayado la parte particularmente problemática de cada entrada, en caso de haber solo una.

5. Esta representación de la cultura japonesa en relación con la violencia era ya común en la década de los ochenta en parte de Europa, como constata el estudio de Kōma (2009) sobre los estereotipos violentos aplicados a los diseñadores de moda japoneses en los dos principales diarios de Francia.

\section{Referencias bibliográficas}

Allport, G. W. (1954). The Nature of Prejudice. Reading: Addison-Wesley.

Blank, A. (1999). Why do new meanings occur? A cognitive typology of the motivations for lexical semantic change. En A. Blank \& P. Koch (Eds.), Historical Semantics and Cognition (pp. 61-90), Berlin / New York: Mouton de Gruyter.

Bloomfield, L. (1933 [1984]). Language. New York: Allen \& Unwin.

Buenafuentes de la Mata, C. \& Sánchez Lancis, C. (2012). El Diccionario del estudiante: la lexicografía académica al servicio de la enseñanza. En A. Nomdedeu Rull, E. Forgas Berdet \& M. Bargalló Escrivà (Eds.), Avances de lexicografía hispánica. Tomo II (pp. 177-189), Tarragona: Publicacions de la Universitat Rovira i Virgili.

Cid Lucas, F. (2009). La presencia de palabras japonesas en el castellano: una lectura antropológica de su incorporación. Observatorio Iberoamericano de la Economía y la Sociedad del Japón, Vol. 1, Núm. 6. 
Coseriu, E. (1977). Lo erróneo y lo acertado en la teoría de la traducción. En El hombre y su lenguaje: estudios de teoría y metodología lingüistica (pp. 214-239), Madrid: Gredos.

Fernández Mata, R. (2016). Los "japonesismos" de la lengua española: historia y transcripción. (Tesis doctoral). Sevilla: Universidad Pablo de Olavide. Recuperado de https://rio.upo.es/xmlui/ handle/10433/3716

Flath, J., Orenga, A., Rubio, C. \& Ueda, H. (2016). Sakura. Diccionario de cultura japonesa: japonésespañol-inglés. Gijón: Satori.

Frago Gracia, J.A. (1997). Japonesismos entre Acapulco y Sevilla: sobre biombo, catana y maque. Boletín de Filología de la Universidad de Chile, XXXVI, 101-108.

Frake, C. O. (1980). Language and cultural description: Essays by Charles O. Frake selected and introduced by Anwar S. Dil. Stanford: Stanford University Press.

García Yebra, V. (1994). Traducción: historia y teoría. Madrid: Gredos.

Giménez Folqués, D. (2012). Los extranjerismos en el español académico del siglo XXI. Normas. Revista de Estudios Lingüisticos Hispánicos (Anejo 3). Valencia: Universitat de València.

Gómez Capuz, J. (1998). El préstamo lingüístico: conceptos, problemas y métodos. Cuadernos de Filología (Anejo 29). Valencia: Universitat de València.

Gómez Capuz, J. (2009). El tratamiento del préstamo lingüístico y el calco en los libros de texto de bachillerato y en las obras divulgativas. Tonos Digital: Revista electrónica de estudios filológicos, 17, 1-24. Recuperado de http://www.tonosdigital.com/ojs/index.php/tonos/article/ viewFile/294/203

Grzega, J. (2003). Borrowing as a word-finding process in cognitive historical onomasiology. Onomasiology Online, 4, 22-42. Recuperado de http://www1.ku-eichstaett.de/SLF/EngluVglSW/ grzega1032.pdf

Grzega, J. \& Schöner, M. (2007). English and general historical lexicology: materials for onomasiology seminars. Eichstätt: Katholische Universität Eichstätt-Ingolstadt. Recuperado de http://www1.ku-eichstaett.de/SLF/EngluVglSW/OnOnMon1.pdf

Hatim, B. \& Mason, I. (1997). The translator as communicator. London / New York: Routledge.

Hirai, M. (2000). "Nihonjin-rashisa" ni tsuite no sutereotaipu: "ippan no nihonjin" to "jibun jishin" to no sai. Jikken shakai shinrigaku kenkyū, 39 (2), 103-113.

Hourani Martín, D. (2012). El tratamiento ortográfico, ortotipográfico y lexicográfico de los extranjerismos crudos en la prensa escrita española. Normas. Revista de Estudios Lingüisticos Hispánicos, 2, 125-156.

Hurtado Albir, A. (1996). La traductología: lingüística y traductología. TRANS. Revista de Traductología, 1, 151-160.

Hurtado Albir, A. (2001). Traducción y Traductología: Introducción a la Traductología. Madrid: Cátedra.

Katan, D. (2009). Translation as intercultural communication. En J. Munday (Ed.), The Routledge Companion to Translation Studies (pp. 74-92), London / New York: Routledge.

Katata, J. (1984-1994). Rōjin Iki. En Nihon Daihyakka Zensho Nipponika. Shogakukan.

Kawasaki, I. (1955). The Japanese are like that. Rutland / Tokyo: C.E. Tuttle.

Kim, T.W. (1992). Análisis lingüístico de los japonesismos en «Triunfo de la fee en los reynos de Japón», de Lope de Vega. En Actas del II Congreso Internacional de Historia de la Lengua española, 1, 1355-1358.

Kōma, K. (2009). Mōdo to ibunka-kan sutereotaipu: Futsu-shinbun (1981-1992) ni okeru nihonjin dezainā no hyōshō: gensetsu bunseki ni yoru apurōchi. Nihon furansugo kyōiku gakkai, 4 (2), 124-132.

Kussmaul, P. (1995). Training the Translator. Amsterdam / Philadelphia: John Benjamins.

Lévi-Strauss, C. (2011). Reconocimiento de la diversidad cultural: lo que nos enseña la civilización japonesa. En C. Lévi-Strauss, La antropología frente a los problemas del mundo moderno (pp. 137-188), Buenos Aires: Libros del Zorzal. Trad.: Agustina Blanco. 
Nerlich, B. (1992). Semantic Theories in Europe 1830-1930. From Etymology to Contextuality. Amsterdam / Philadelphia: John Benjamins.

Nida, E. A. (1990). Lengua, cultura y traducción. En M. A. Vega Cernuda \& R. Martín-Gaitero (Eds.), Lengua y cultura: estudios en torno a la traducción (pp. 1-7), [Madrid]: Instituto Universitario de Lenguas Modernas y Traductores [Universidad Complutense].

Nord, C. (1991). Text Analysis in Translation. Amsterdam / New York: Rodopi.

Nord, C. (1996). El error en la traducción: categorías y evaluación. En A. Hurtado Albir (Ed.), La enseñanza de la traducción (pp. 91-108), Castellón: Servicio de Publicaciones, Universitat Jaume I.

Nord, C. (1998). La unidad de traducción en el enfoque funcionalista. Quaderns: Revista de traducció, $1,65-77$.

Nord, C. (2010 [2013]). Functionalist approaches. En Y. Gambier \& L. van Doorslaer (Eds.), Handbook of Translation Studies (pp. 120-128), Amsterdam / Philadelphia: John Benjamins.

Palazuelos, J.C., Vivanco, H., Hörmann, P. \& Garbarini, C.G. (1992). El error en traducción. Santiago de Chile: Pontificia Universidad Católica de Chile.

Pym, A. (1992). Translation error analysis and the interface with language teaching. En C. Dollerup \& A. Loddegaard (Eds.), The Teaching of Translation (pp. 279-288), Amsterdam: John Benjamins.

Pym, A. (1995). Schleiermacher and the Problem of Blendlinge. Translation and Literature, 4 (1), 5-30.

RAE/Real Academia Española (2014). Diccionario de la lengua española. http://dle.rae.es

Reiss, K. \& Vermeer, H. (1996). Fundamentos para una teoría funcional de la traducción. Madrid: Akal.

Reyes Díaz, M.J. (2004). A propósito de léxico y cultura. En S. Bravo Utrera (Ed.), Traducción, Lenguas, Literaturas (pp. 221-234), Servicio de Publicaciones de la Universidad de Las Palmas de Gran Canaria.

Seco, M. (1977). El léxico de hoy. En R. Lapesa Melgar (Coord.), Comunicación y lenguaje (pp. 181202), Madrid: Karpos.

Stern, G. (1931). Meaning and change of meaning: with special reference to the English language. Göteborg: Elander.

Ullmann, S. (1951). Words and their use. New York: Philosophical Library.

Ullmann, S. (1962). Semantics: An introduction to the science of meaning. Oxford: Blackwell.

Vermeer, H. (1992). Is translation a linguistic or a cultural process? Ilha do desterro. Studies in Translation, 28, 37-51.

Waddington, C. (2001). Estudio comparativo de diferentes métodos de evaluación de traducción general (Inglés-Español). Madrid: Universidad Pontificia Comillas.

\section{Perfil del autor}

Alberto Millán Martín es doctor en Estudios Japoneses por la Universidad de Osaka y licenciado en Traducción e Interpretación por la Universidad Autónoma de Barcelona. Es profesor titular de español en la Facultad de Economía de la Universidad Keio en Tokio y Yokohama, donde también imparte clases de estudios culturales comparativos y seminarios sobre historia japonesa y teoría de la traducción. Sus investigaciones se centran en el papel que han desempeñado la traducción y el uso del lenguaje en la evolución de la civilización japonesa y en su relación con otras culturas. 


\section{Abstract}

Despite of an increasing number of Japanese loanwords entering the Spanish language, there is no qualitative research on whether the transfer of concepts from one culture to the other has been executed rigorously enough to allow us to properly understand the idiosyncrasy of Japanese civilization. This research paper explores the main problems found in the lexicalization of Japanese cultural terms, focusing on semantic errors, as seen in the case study of the Sakura dictionary by Spanish publisher Satori (2016), a unique Spanish-language reference work specialized in Japanese culture and compiled with the collaboration of numerous scholars and professionals. On the basis of our threefold theoretical framework -linguistic change, translation studies, and intercultural communication-, we propose a typology of errors consisting of non-exclusive categories that can serve as a checklist to detect and avoid similar mistakes in future publications.

\section{Keywords}

Loanword, Japanese-Spanish, cultural marker, translation, error analysis

\section{要旨}

スペイン語において日本語からの外行語は年々増加の傾向にある。しかし、日本文化からスペ イン文化への概念の移動が、日本文化の特質を適切に理解し得るような正確な方法で行われた かどうかを分析した質的研究は存在しない。従って、本研究では、日本文化に関する語が語彙化 される際に見られる諸問題について、特に意味論上の誤りに焦点を当てて考察した。資料体とし ては、多くの専門家の協力により編纂され、スペイン語で唯一の学術的専門書である日本文化辞 典Sakura（2016)を取り上げた。本研究において、言語変化、翻訳研究、異文化コミュニケーション の3つの理論的枠組みに基づいた分析の結果、類似の詋り防止に寄与すべく、誤りの類型を示し ている。

キーワード

借用語、外行語、文化的標識、翻訳、詋り分析 